\title{
Cleaning products and asthma risk: a potentially important public health concern
}

\author{
Elissa M. Abrams MD
}

— Cite as: CMAJ 2020 February 18;192:E164-5. doi: 10.1503/cmaj.200025

See related article at www.cmaj.ca/lookup/doi/10.1503/cmaj.190819

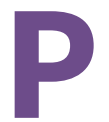

revalence of pediatric asthma in Canada is $13 \%$ and has increased over time. ${ }^{1}$ Asthma often begins early in childhood, and lifelong complications, including airway remodelling, can begin as early as the preschool years. ${ }^{2,3}$ As a result, focus on possible means of asthma prevention has increased. In linked research, Parks and colleagues describe an association between use of household cleaning products early in life and risk of childhood wheeze and asthma at age 3 years, using data from the Canadian Healthy Infant Longitudinal Development (CHILD) Cohort Study. ${ }^{4}$ This longitudinal prospective birth cohort of 3455 participants notes that children had a higher odds of recurrent wheeze, recurrent wheeze with atopy and asthma diagnosis if living in homes with a higher frequency of use of cleaning products during their infancy. Several studies have identified household cleaning products to be associated with elevated risk of asthma or wheeze in adolescents, in adults and in association with occupational exposures, ${ }^{5}$ and the linked study adds to this by showing an association in young children. The study also contributes to a growing concern about the likely irritative effects of commonly used cleaning products on the respiratory system.

Asthma is increasingly understood to develop early in life and progress over time, with only a small window in early childhood during which preventive efforts may be beneficial, as airway remodelling can begin in the early toddler years with lifelong sequelae. For example, studies have noted evidence of airway remodelling, such as increased reticular basement membrane thickness and eosinophilic inflammation in endobronchial biopsies of toddlers (median age 29 months) with recurrent wheeze. ${ }^{3}$ Strikingly, long-term follow-up within the Childhood Asthma Management Program (CAMP) study of 1041 children aged 5-12 years with mild to moderate asthma showed that $75 \%$ of these children had abnormal patterns of lung growth and $11 \%$ met criteria for chronic obstructive pulmonary disease in their twenties. ${ }^{2}$ Therefore, studies that identify avoidable factors to inform asthma prevention efforts are of paramount importance. The linked study points to small preventive changes that could be considered, especially among families of children at risk of asthma. ${ }^{4}$

\section{KEY POINTS}

- A linked cohort study notes an association between use of household cleaning products early in life and risk of childhood wheeze and asthma at age 3 years.

- Accumulating evidence shows that household cleaning products increase the risk of asthma or wheeze across age groups.

- Chemicals in household cleaning products are currently underregulated in North America.

- Further research is required to examine the longer-term impacts of exposure to such products early in life on the developing airways of young children and any phenotypic variation in sequelae.

Given the accumulating evidence, ${ }^{5}$ the American Lung Association recommends using only cleaning products that "don't have volatile organic compounds, fragrances, irritants or flammable ingredients" and that air fresheners should be avoided altogether. ${ }^{6}$ However, currently, manufacturers in Canada and the United States are not required to list all ingredients in consumer household cleaning products, and even products labelled as "environmentally friendly" or "green" may contain harmful substances, as such claims are largely unregulated. ${ }^{6}$ Changes in regulation are occurring in other jurisdictions, such as the European Union, where it is now required that labels on cleaning products must warn consumers about possible toxic ingredients within these products. ${ }^{7}$

Parks and colleagues ${ }^{4}$ note that some of the consumer products associated with highest risk were scented. Other studies have also found that particularly scented or air-refreshing products are associated with the highest respiratory risk. For example, follow-up within the European Community Respiratory Health Survey of 3503 adults doing cleaning in their homes who were free of asthma at baseline noted that the use of cleaning sprays at least once a week was associated with incidence of asthma symptoms or use of asthma medications (relative risk [RR] 1.49, 95\% Cl 1.12-199), with one of the highest risk products being air-refreshing sprays (RR current asthma 1.71 , 95\% Cl 1.222.39). ${ }^{8}$ In this large observational study, about 1 in 7 cases of 
adult asthma could be attributed to use of common sprays. As such, removal of scented products from the homes of families of children at risk of asthma, or with current asthma symptoms, is likely wise.

It is well known that early childhood wheeze may not predict long-term asthma. Although atopy is the strongest risk factor for persistence of asthma in childhood and the linked study showed increased rates of atopic wheeze at age 3 years for children from homes with high use of cleaning products, most children outgrow asthma symptoms by school age. ${ }^{9}$ Studies looking at longer-term outcomes including into school age are required to accurately predict the long-term and chronic burden that such airway irritants may pose to the developing airways of young children.

Another remaining question is whether cleaning products predispose individuals to, or worsen, a specific asthma phenotype. There are different asthma phenotypes and the effects of such agents appear to be irritant. It may be that there is a subtype of irritant asthma that is largely preventable, which means - as cleaning products are ubiquitous - that a widespread public health education campaign may be required to bolster prevention. ${ }^{10}$

The linked research requires replication in other pediatric cohort studies. For this purpose, a singular, validated measure of indoor pollution from cleaning products would be beneficial. Furthermore, the study points to a larger issue within the field, which is the identification of early life exposures that may modify the risk of childhood asthma. In the meantime, this study supports a growing call to action on the role of cleaning products in irritating the airways of young children.

\section{References}

1. Garner R, Kohen D. Changes in the prevalence of asthma among Canadian children. Health Rep 2008;19:45-50.

2. McGeachie MJ, Yates KP, Zhou X, et al. Patterns of growth and decline in lung function in persistent childhood asthma. N Engl J Med 2016;374:1842-52.

3. Saglani S, Payne DN, Zhu J, et al. Early detection of airway wall remodeling and eosinophilic inflammation in preschool wheezers. Am J Respir Crit Care Med 2007;176:858-64.

4. Parks J, McCandless L, Dharma C, et al. Association of use of cleaning products with respiratory health in a Canadian birth cohort. CMAJ 2020;192:E154-61.

5. Folletti I, Siracusa A, Paolocci G. Update on asthma and cleaning agents. Curr Opin Allergy Clin Immunol 2017;17:90-5.

6. Cleaning supplies and indoor chemicals. Chicago: American Lung Association. Available: https://www.lung.org/our-initiatives/healthy-air/indoor/indoor-air -pollutants/cleaning-supplies-household-chem.html (accessed 2019 Dec. 17).

7. EU decision to invoke article 50. Regulation (EC) No 1272/2008 - Classification, packaging and labelling of chemical substances and mixtures. Available: https://eur-lex.europa.eu/legal-content/EN/LSU/?uri=CELEX:32008R1272\&qid $=1457530869587$ (accessed 2019 Dec. 17).

8. Zock J-P, Plana E, Jarvis D, et al. The use of household cleaning sprays and adult asthma: an international longitudinal study. Am J Respir Crit Care Med 2007;176:735-41.

9. Martinez FD, Wright AL, Taussig LM, et al. Asthma and wheezing in the first six years of life. The Group Health Medical Associates. N Engl J Med 1995;332:133-8.

10. Zock J-P, Vizcaya D, Le Moual N. Update on asthma and cleaners. Curr Opin Allergy Clin Immunol 2010;10:114-20.

\section{Competing interests: None declared.}

This article was solicited and has not been peer reviewed.

Affiliations: Department of Pediatrics, Section of Allergy and Clinical Immunology, University of Manitoba, Winnipeg Man., and Department of Pediatrics, Division of Allergy and Immunology, University of British Columbia, Vancouver, BC

Correspondence to: Elissa Abrams, elissa.abrams@gmail.com 